\title{
Novel application of Wiener vis-à-vis Szeged indices: Antitubercular activities of quinolones
}

\author{
VIJAY K AGRAWAL ${ }^{\mathrm{a}}$, SHAHNAZ BANO ${ }^{\mathrm{a}}$, KESHAV C MATHUR ${ }^{\mathrm{a}}$ and \\ PADMAKAR V KHADIKAR*,b \\ a Department of Chemistry, APS University, Rewa 486 003, India \\ ${ }^{\mathrm{b}}$ Research Division, Laxmi Pest \& Fumigation Pvt. Ltd., 3 Khatipura, Indore \\ 452007 , India \\ e-mail: pvkhadikar@yahoo.com
}

MS received 14 June 1999; revised 27 December 1999

\begin{abstract}
The paper gives a brief account of the recently introduced Szeged index (Sz). Using this index antitubercular activities of N-2,4-difluorophenyl quinolones are subjected to quantitative structure-activity relationship analysis. The potential of $\mathrm{Sz}$ related to the Wiener index (W) is critically discussed. In addition, Huckel molecular orbital energies: $E_{\mathrm{HOMO}}, E_{\mathrm{LUMO}}$ and $E_{\text {total }}$ were also used for comparing and modelling antitubercular activities of the quinolones. The results, based on univariate as well as multivariate regressions, have shown that $\mathrm{W}, \mathrm{Sz}$ and $E_{\text {total }}$ give better results and that the correlations improve in multivariate regression analyses.
\end{abstract}

Keywords. Quantitative structure-activity relationship; Wiener and Szeged indices; antitubercular activity; fluorophenyl quinolones; modelling of drug activity.

\section{Introduction}

Quantitative structure-property-activity (QSPR, QSAR) relationships are certainly not a new field in chemistry. In fact, correlations between molecular properties and many kinds of molecular descriptors have been empirically sought for many years. Usually, molecular descriptors are chosen in an empirical way, that is, according to their ability to give good results in statistical models.

It has been known for some time that certain invariants of molecular graphs (carbon-hydrogen suppressed molecular structure of the organic molecules acting as drugs) - usually referred to as topological indices - can be used to establish quantitative structure-activity relationships (QSAR) of interest in pharmacology ${ }^{1}$. A number of successful QSAR studies have been made based on the Wiener index (W) ${ }^{2-4}$ and its decomposition forms ${ }^{5}$. This index was introduced fifty years ago and looked upon as a measure of compactness of molecules but only recently ${ }^{6}$ its relation with the molecular van der Waals area was demonstrated.

Recently ${ }^{7,8}$ Gutman proposed a new index which was named the Szeged index (Sz). Many properties of $\mathrm{Sz}$ are discussed ${ }^{9-11}$ but its applications in QSAR studies have not been thoroughly investigated.

*For correspondence 
As part of a study optimize the quinolone antibacterials against $M$. tuberculosis, Renau and coworkers ${ }^{12}$ have synthesized a series of $\mathrm{N}$-2,4-difluorophenyl quinolones and evaluated a variety of $\mathrm{C} 7$ substituted quinolones with varying degrees of substitution and lipophilicity on the heterocyclic side chain (table 1). In order to investigate the relative antituberculotic activities of these compounds, they have calculated $c \log P$ values (table 1). However, no attempt has been made to investigate QSAR using molecular (topological and quantum mechanical) descriptors.

In view of the above, it was considered worthwhile to investigate the potential of $\mathrm{Sz}$ in QSAR studies. The main objective of this paper is to show how useful Sz can be in the QSAR field, both from the theoretical and the practical point of view. In order to investigate the relative potential of Sz over W in QSAR studies, an attempt is also made to study the role of $\mathrm{W}$ in modelling antitubercular activities of the quinolones. The Huckel orbital energies, the energy of the highest occupied molecular orbital $\left(E_{\text {Номо }}\right)$, the energy of the lowest unoccupied molecular orbital energy $\left(E_{\mathrm{LUMO}}\right)$ and total $\pi$-electron energy $\left(E_{\text {total }}\right)$ are used as molecular descriptors. Note that the Wiener $(\mathrm{W})$ and Szeged (Sz) indices are graph theoretical descriptors and these are merely topological in nature. On the other hand, HOMO and LUMO orbital energies are quantum chemical properties. These two parameters are not related (see table 2). However, we have used Sz and W indices because the potential of $\mathrm{Sz}$ in developing QSAR relationships is not well-known and this is our main objective. Another objective of the present investigation is to

Table 1. N-2,4-difluorophenyl quinolones used in the present study and their $c \log P$ values, Wiener (W)- and Szeged (Sz) indices (ref. figure 1).

$\mathrm{R}=$ substitution at $\mathrm{R}$ in figure $1 ; c \log P=\operatorname{logarithm}$ of partition coefficient $(P)$ in octanol-water; $\mathrm{W}=$ Wiener index; $\mathrm{Sz}=$ Szeged index.

\begin{tabular}{|c|c|c|c|c|c|}
\hline Compound & $\mathrm{R}$ & $c \log P$ & W & $\mathrm{Sz}$ & $\mathrm{Sz} / \mathrm{W}$ \\
\hline I & & $3 \cdot 81$ & 2302 & 4456 & 1.93571 \\
\hline II & & 4.67 & 2302 & 4456 & 1.93571 \\
\hline III & & 3.33 & 2437 & 4735 & 1.94296 \\
\hline IV & & 4.85 & 2468 & 5108 & 2.06969 \\
\hline V & & 4.86 & 2732 & 5242 & 1.91874 \\
\hline VI & & $5 \cdot 20$ & 2386 & 4622 & 1.93713 \\
\hline VII & & 5.51 & 2773 & 5285 & 1.90588 \\
\hline VIII & & $6 \cdot 12$ & 2965 & 5518 & $1 \cdot 86105$ \\
\hline IX & & $6 \cdot 24$ & 3200 & 5901 & 1.84406 \\
\hline
\end{tabular}


Table 2. Correlation matrix for the correlation of $c \log P$ of $\mathrm{N}-2,4$-difluorophenyl quinolones with various parameters used in the present study. $c \log P=\log$ arithm of partition coefficient $(P)$ in octanol-water; $\mathrm{W}=$ Wiener index; $\mathrm{Sz}=$ Szeged index; $E_{\mathrm{HOMO}}=$ highest occupied molecular orbital energy, $E_{\mathrm{LUMO}}=$ lowest unoccupied molecular orbital energy, $\delta E=$ energy difference between $E_{\mathrm{HOMO}}$ and $E_{\mathrm{LUMO}} ; E_{\mathrm{total}}=$ total $\pi$-electron energy, all energies in $\beta$ units.

\begin{tabular}{lrrrrrrr}
\hline & \multicolumn{1}{c}{$c \log P$} & $\mathrm{~W}$ & \multicolumn{1}{c}{$\mathrm{Sz}$} & $E_{\text {HOMO }}$ & $E_{\text {LUMO }}$ & $E_{\text {total }}$ & $\delta E$ \\
\hline$c \log P$ & $1 \cdot 00000$ & & & & & & \\
$\mathrm{~W}$ & $0 \cdot 86762$ & $1 \cdot 00000$ & & & & & \\
$\mathrm{Sz}$ & 0.84355 & 0.97050 & $1 \cdot 00000$ & & & & \\
$E_{\text {HOMO }}$ & -0.22464 & -0.06078 & $-0 \cdot 16381$ & $1 \cdot 00000$ & & & \\
$E_{\mathrm{LUMO}}$ & $0 \cdot 04518$ & $0 \cdot 23644$ & $0 \cdot 17733$ & 0.64958 & $1 \cdot 00000$ & & \\
$E_{\text {total }}$ & 0.96785 & 0.92913 & 0.93146 & -0.17025 & $0 \cdot 16018$ & 1.0000 & \\
$\delta E$ & -0.33394 & -0.28129 & -0.36646 & 0.76213 & 0.00283 & -0.36033 & 1.0000 \\
\hline
\end{tabular}<smiles>[R]c1cc2c(cc1F)c(=O)c(C(=O)O)cn2-c1ccc(F)cc1F</smiles>

Figure 1. Structure of the quinolones under study.

compare the results obtained from $\mathrm{Sz}$ with those obtained from W. The reason for using $E_{\mathrm{HOMO}}$ and $E_{\mathrm{LUMO}}$ is that, most commonly, the dependence of biological activity on these parameters has been attributed to their being a measure of the ability of a molecule to serve as an electron donor (HOMO) or an electron acceptor (LUMO) in the formation of charge transfer (or electron donor-acceptor) complexes ${ }^{13}$. Dependence on the difference between these two energies may be accounted for by the relationship of this difference to the hardness in the context of hard and soft acids and bases ${ }^{14,15}$. Thus, the use of two types of unrelated parameters give two different types of information in developing QSAR models. The results are discussed below.

\section{Computational procedure: Molecular modelling}

Prompted by the observation ${ }^{11}$ that N-2,4-difluorophenyl quinolones can be used in chemotherapy against $M$. tuberculosis, we studied a group of these quinolones (figure 1).

We studied these quinolones because they and their derivatives exhibit interesting biological and chemical properties which may eventually lead to useful applications. The nine quinolones selected for study are listed in table 1, along with values of the corresponding antitubercular activities (in terms of $c \log P$ ), W and Sz. Modifications were allowed only at the $\mathrm{C} 7$ position. The size of the derivatives is varied by using different piperazyl and pyrrolidine side chains having varying degrees of alkyl substitution. 
Our approach has been to calculate a number of $\mathrm{Sz}, \mathrm{W}$ and molecular orbital energies, and to test each of these parameters using univariate as well as multivariate regression analyses. A correlation coefficient between 0.8 and 0.9 is considered "good" and values that are higher $(>0.98)$ are "excellent". Those parameters are retained which have at least good correlation with antitubercular activities and yield physically meaningful regressions. These relationships are then interpreted for their possible significance in formulating interesting models, and subsequently are used to develop multivariate regressions.

(i) Wiener index $(W)$ : If $\mathrm{d}(u, v \mid G)$ is the distance ${ }^{16}$ between the vertices $u$ and $v$ of the graph $G$ (i.e. the number of edges in the shortest path that connects $u$ and $v$ ), $V(G)$ is the vertex set of $G$, then

$$
\mathrm{W}=\mathrm{W}(G)=\frac{1}{2} \sum_{e \in V(G)} \sum_{v \in V(G)} \mathrm{d}(u, v \mid G) .
$$

For acyclic molecular graphs, Wiener ${ }^{2}$ discovered a remarkably simple method for the calculation of W. Let $e$ be an edge of an acyclic molecular graph $G$ (= a tree). Let $n_{1}(e \mid G)$ and $n_{2}(e \mid G)$ be the number of vertices of $G$ lying on two sides of the edge $e$. Then

$$
\mathrm{W}=\mathrm{W}(G)=\sum_{e \in E(G)} n_{1}(e \mid G) n_{2}(e \mid G) .
$$

Here $E(G)$ denotes the edge set of the graph $G$.

(ii) Szeged index (Sz): In developing the Sz index, the quantities $n_{1}(e \mid G)$ and $n_{2}(e \mid G)$ are formally written as follows: Let $e$ be an edge of a graph $G$ (which may contain cycles or be acyclic) connecting the vertices $u$ and $v$. Define two sets $N_{1}(e \mid G)$ and $N_{2}(e \mid G)$ as

$$
\begin{aligned}
& N_{1}(e \mid G)=\{x \in V(G) \mid \mathrm{d}(x, u \mid G)<\mathrm{d}(x, v \mid G)\}, \\
& N_{2}(e \mid G)=\{x \in V(G) \mid \mathrm{d}(x, v \mid G)<\mathrm{d}(x, u \mid G)\} .
\end{aligned}
$$

The number of elements of $N_{1}(e \mid G)$ and $N_{2}(e \mid G)$ are denoted by $n_{1}(e \mid G)$ and $n_{2}(e \mid G)$ respectively. Thus, $n_{1}(e \mid G)$ counts the vertices of $G$ lying closer to the vertex $u$ than to vertex $v$. The meaning of $n_{2}(e \mid G)$ is analogous. Vertices equidistant from both ends of the edge $u v$ belong neither to $N_{1}(e \mid G)$ nor to $N_{2}(e \mid G)$.

The Szeged index of the graph $G$ is defined as:

$$
\mathrm{Sz}(G)=\mathrm{Sz}=\sum_{e \in E(G)} n_{1}(e \mid G) n_{2}(e \mid G) .
$$

This generalization (5), was conceived by Gutman at the Attila Jozsef University in Szeged, and we propose that it be called the Szeged index, denoted by $\mathrm{Sz}^{7}$.

The basic properties of $\mathrm{Sz}$ were recently established and it was found to be endowed with interesting and mathematically appealing features ${ }^{6-11}$. In this paper, we point out the potential of Sz in QSAR studies and in modelling the physiological activities of organic compounds acting as drugs i.e. the quinolones. 
Table 3. Huckel molecular orbital energies: $E_{\mathrm{HOMO}}, E_{\mathrm{LUMO}}, E_{\text {total }}$ and $\delta E\left(=E_{\mathrm{HOMO}}-\right.$ $E_{\text {LUMO }}$ ) values for $\mathrm{N}-2,4$-difluorophenyl quinolones.

$E_{\mathrm{HOMO}}=$ energy of highest occupied molecular orbital, $E_{\mathrm{LUMO}}=$ energy of lowest unoccupied molecular orbital, $\delta E=$ energy difference between $E_{\mathrm{HOMO}}$ and $E_{\mathrm{LUMO}}$, $E_{\text {total }}=$ total $\pi$-electron energy, all in $\beta$ units.

\begin{tabular}{lcccc}
\hline Compound & $E_{\text {HOMO }}$ & $E_{\text {LUMO }}$ & $\delta E$ & $E_{\text {total }}$ \\
\hline I & 0.5643 & -0.0601 & 0.6248 & 61.7018 \\
II & 0.2303 & -0.4528 & 0.6831 & 62.3158 \\
III & 0.2730 & -0.2607 & 0.5337 & 62.7178 \\
IV & 0.0000 & -0.3650 & 0.3650 & 63.9273 \\
V & 0.5643 & -0.0540 & 0.6183 & 64.1928 \\
VI & 0.5643 & -0.0528 & 0.6171 & 64.0648 \\
VII & 0.0000 & -0.0564 & 0.0564 & 64.8805 \\
VIII & 0.0000 & -0.3787 & 0.3787 & 66.1204 \\
IX & 0.5626 & -0.0489 & 0.6115 & 66.5975 \\
\hline
\end{tabular}

(iii) $E_{\text {Номо }}, E_{L U M O}$ and $E_{\text {total }}$ orbital energies: Along with Sz, frontier orbital energies: the energy of the highest occupied molecular orbital, $\left(E_{\mathrm{HOMO}}\right)$, the energy of the lowest unoccupied molecular orbital energy $\left(E_{\mathrm{LUMO}}\right)$, and the total $\pi$-electron energy $\left(E_{\text {total }}\right)$, were also used as molecular parameters for modelling the activities of N-2,4-difluorophenyl quinolones. These energies were calculated from the HMO version 1.1 supplied by Wissner ${ }^{17}$. The data so obtained are recorded in table 3 . The values of these energies are given in terms of $\beta$.

(iv) Regression analysis: Regression analysis for modelling the activities of N-2,4difluorophenyl quinolones was carried out using Regress-1 software. The correlation matrix derived from this program is given in table 2. Regression parameters as well as the quality of different monovariate and multivariate correlations are recorded in table 4 . The extent of modelling is summarized in table 5 .

\section{Results and discussion}

Renau and coworkers ${ }^{12,16-18}$ have reported the effect of changes in the lipophilicity of $\mathrm{N}$-phenyl substituted fluoroquinolones against microbacteria. The issue of penetration of these compounds into microbacteria is important in the design of new antitubercular agents since it is well-known that surface-associated lipids of microbacteria form a transport barrier when compared to the cell wall of true bacteria. They have demonstrated that increasing the lipophilic character of the side chain at $\mathrm{C} 7$ may be more important in exhibiting antitubercular activities of the quinolones.

To test the aforementioned possibilities a quantitative model of the structure-activity relation must be found. The choice of the structural parameters is necessarily somewhat arbitrary. However, for the reasons mentioned earlier we have chosen topological indices $\mathrm{W}$ and $\mathrm{Sz}$ as well as frontier orbital energies. To make correlation calculation possible, carbon-hydrogen suppressed molecular graphs of the quinolones were considered.

It is worthy of mention that higher values of hardness at constant chemical potential indicate higher stability ${ }^{13-15,19,20}$. A perusal of table 2 indicates that HOMO, LUMO orbital energies from this point of view (i.e. $E_{\mathrm{HOMO}}-E_{\mathrm{LUMO}}=\delta E$ ) do not correlate with the 
Table 4. Regression parameters and the quality of correlation of $c \log P$ with $\mathrm{Sz}$, $E_{\mathrm{HOMO}}, E_{\mathrm{LUMO}}, E_{\text {total }}$ and $\delta E$ in univariate and multivariate regressions for N-2,4difluorophenyl quinolones.

$A, B=$ regression parameters, $\mathrm{SD}=$ standard deviation (standard error of estimation), $R=$ correlation coefficient, $c \log P=\operatorname{logarithm}$ of partition coefficient $(P)$ in octanolwater, $\mathrm{W}=$ Wiener index, $\mathrm{Sz}=$ Szeged index, $E_{\mathrm{HOMO}}=$ highest occupied molecular orbital energy, $E_{\mathrm{LUMO}}=$ lowest unoccupied molecular orbital energy, $\delta E=$ energy difference between $E_{\mathrm{HOMO}}$ and $E_{\mathrm{LUMO}}, E_{\mathrm{total}}=$ total $\pi$-electron energy, all energies in $\beta$ units.

\begin{tabular}{|c|c|c|c|c|c|}
\hline $\begin{array}{l}\text { Correlation } \\
\text { parameters used }\end{array}$ & $\begin{array}{c}\text { Slope } A_{i} \\
i=1-4\end{array}$ & Intercept $B$ & SD & $R$ & $F$-ratio \\
\hline W & $A=0.0022$ & -0.6476 & 0.4241 & 0.8676 & $21 \cdot 314$ \\
\hline $\mathrm{Sz}$ & $A=0.0013$ & -0.6703 & 0.4581 & 0.8435 & $17 \cdot 269$ \\
\hline$E_{\text {total }}$ & $A=0.4692$ & $-24 \cdot 9891$ & $0 \cdot 2145$ & 0.9679 & $103 \cdot 652$ \\
\hline $\begin{array}{l}\mathrm{W} \\
E_{\text {НОМо }}\end{array}$ & $\begin{array}{l}A_{1}=0.0022 \\
A_{2}=-0.5233\end{array}$ & $-0 \cdot 4181$ & 0.4297 & 0.8846 & $10 \cdot 789$ \\
\hline $\begin{array}{l}\mathrm{W} \\
E_{\mathrm{LUMO}}\end{array}$ & $\begin{array}{l}A_{1}=0.0023 \\
A_{2}=-0.7937\end{array}$ & $-1 \cdot 0641$ & 0.4323 & 0.8831 & $10 \cdot 628$ \\
\hline $\begin{array}{l}\mathrm{W} \\
\delta E\end{array}$ & $\begin{array}{l}A_{1}=0.0021 \\
A_{2}=-0.3891\end{array}$ & $-0 \cdot 2726$ & 0.4491 & 0.8727 & $9 \cdot 581$ \\
\hline $\begin{array}{l}\mathrm{W} \\
E_{\text {total }}\end{array}$ & $\begin{array}{l}A_{1}=-5.821 \times 10^{-4} \\
A_{2}=0.5734\end{array}$ & $-30 \cdot 1425$ & 0.2179 & 0.9716 & $50 \cdot 630$ \\
\hline $\begin{array}{l}\mathrm{Sz} \\
E_{\mathrm{HOMO}}\end{array}$ & $\begin{array}{l}A_{1}=0 \cdot 0013 \\
A_{2}=-0 \cdot 2694\end{array}$ & $-1 \cdot 4715$ & 0.4882 & $0 \cdot 8481$ & $7 \cdot 686$ \\
\hline $\begin{array}{l}\mathrm{Sz} \\
E_{\mathrm{LUMO}}\end{array}$ & $\begin{array}{l}A_{1}=0.0014 \\
A_{2}=-0.5049\end{array}$ & $-1 \cdot 9200$ & 0.4851 & $0 \cdot 8502$ & $7 \cdot 824$ \\
\hline $\begin{array}{l}\mathrm{Sz} \\
\delta E\end{array}$ & $\begin{array}{l}A_{1}=0.0013 \\
A_{2}=-0.1143\end{array}$ & $-1 \cdot 5249$ & 0.4942 & $0 \cdot 8440$ & $7 \cdot 427$ \\
\hline $\begin{array}{l}\mathrm{Sz} \\
E_{\text {total }}\end{array}$ & $\begin{array}{l}A_{1}=-6.9445 \times 10^{-4} \\
A_{2}=0.6669\end{array}$ & $-34 \cdot 1581$ & $0 \cdot 1793$ & 0.9809 & $76 \cdot 206$ \\
\hline $\begin{array}{l}\delta E \\
E_{\text {total }}\end{array}$ & $\begin{array}{l}A_{1}=0.0679 \\
A_{2}=0.4721\end{array}$ & $-25 \cdot 2134$ & $0 \cdot 2313$ & 0.9680 & $44 \cdot 612$ \\
\hline $\begin{array}{l}\mathrm{W} \\
\mathrm{Sz} \\
E_{\text {total }}\end{array}$ & $\begin{array}{l}A_{1}=6 \cdot 7709 \times 10^{-4} \\
A_{2}=-0.0010 \\
A_{3}=0.6421\end{array}$ & $-32 \cdot 6369$ & $0 \cdot 1861$ & 0.9828 & $47 \cdot 335$ \\
\hline $\begin{array}{l}\mathrm{W} \\
E_{\text {HOMO }} \\
E_{\text {total }}\end{array}$ & $\begin{array}{l}A_{1}=-5 \cdot 0797 \times 10^{-4} \\
A_{2}=-0.1255 \\
A_{3}=0.5567\end{array}$ & $-29 \cdot 2286$ & $0 \cdot 2354$ & 0.9724 & 28.924 \\
\hline $\begin{array}{l}\mathrm{W} \\
E_{\mathrm{LUMO}} \\
E_{\text {total }}\end{array}$ & $\begin{array}{l}A_{1}=-4.2490 \times 10^{-4} \\
A_{2}=-0.4570 \\
A_{3}=0.5528\end{array}$ & $-29 \cdot 3236$ & $0 \cdot 2193$ & 0.9761 & 33.644 \\
\hline $\begin{array}{l}\mathrm{W} \\
\delta E \\
E_{\text {total }}\end{array}$ & $\begin{array}{l}A_{1}=-6 \cdot 1367 \times 10^{-4} \\
A_{2}=0 \cdot 1277 \\
A_{3}=0.5846\end{array}$ & $-30 \cdot 8435$ & $0 \cdot 2368$ & 0.9721 & 28.599 \\
\hline $\begin{array}{l}\mathrm{Sz} \\
E_{\mathrm{HOMO}} \\
E_{\text {total }}\end{array}$ & $\begin{array}{l}A_{1}=-6.9846 \times 10^{-4} \\
A_{2}=-0 \cdot 1942 \\
A_{3}=0.6627\end{array}$ & $-33 \cdot 8131$ & $0 \cdot 1858$ & 0.9828 & 47.499 \\
\hline
\end{tabular}


Table 4. (Contd)

\begin{tabular}{|c|c|c|c|c|c|}
\hline $\begin{array}{l}\text { Correlation } \\
\text { parameters used }\end{array}$ & $\begin{array}{c}\text { Slope } A_{i} \\
i=1-4\end{array}$ & Intercept $B$ & SD & $R$ & $F$-ratio \\
\hline $\begin{array}{l}\mathrm{Sz} \\
E_{\mathrm{LUMO}} \\
E_{\text {total }}\end{array}$ & $\begin{array}{l}A_{1}=6 \cdot 6051 \times 10^{-4} \\
A_{2}=-0.4718 \\
A_{3}=0.6650\end{array}$ & $-34 \cdot 3017$ & $0 \cdot 1690$ & 0.9859 & 57.742 \\
\hline $\begin{array}{l}\mathrm{Sz} \\
\delta E \\
E_{\text {total }}\end{array}$ & $\begin{array}{l}A_{1}=-6.9389 \times 10^{-4} \\
A_{2}=0.0061 \\
A_{3}=0.6670\end{array}$ & $-34 \cdot 1707$ & $0 \cdot 1964$ & 0.9809 & $42 \cdot 337$ \\
\hline $\begin{array}{l}E_{\mathrm{HOMO}} \\
E_{\mathrm{LUMO}} \\
E_{\text {total }}\end{array}$ & $\begin{array}{l}A_{1}=0.0996 \\
A_{2}=-0.6350 \\
A_{3}=0.4824\end{array}$ & -25.9896 & $0 \cdot 2264$ & 0.9745 & 31.444 \\
\hline $\begin{array}{l}E_{\mathrm{HOMO}} \\
\delta E \\
E_{\text {total }}\end{array}$ & $\begin{array}{l}A_{1}=-0.5354 \\
A_{2}=0.6350 \\
A_{2}=0.4824\end{array}$ & -25.9896 & 0.2264 & 0.9745 & $31 \cdot 444$ \\
\hline $\begin{array}{l}\mathrm{W} \\
\mathrm{Sz} \\
\delta E \\
E_{\text {total }}\end{array}$ & $\begin{array}{l}A_{1}=7.7369 \times 10^{-4} \\
A_{2}=-0.0011 \\
A_{3}=-0.1048 \\
A_{4}=0.6367\end{array}$ & $-32 \cdot 2018$ & $0 \cdot 2065$ & 0.9831 & $28 \cdot 855$ \\
\hline $\begin{array}{l}\mathrm{W} \\
E_{\mathrm{LUMO}} \\
\delta E \\
E_{\text {total }}\end{array}$ & $\begin{array}{l}A_{1}=-4.5780 \times 10^{-4} \\
A_{2}=-0.4617 \\
A_{3}=0.1399 \\
A_{4}=0.5649\end{array}$ & $-30 \cdot 0829$ & $0 \cdot 2424$ & 0.9766 & $20 \cdot 665$ \\
\hline $\begin{array}{l}\mathrm{W} \\
E_{\text {HOMO }} \\
\delta E \\
E_{\text {total }}\end{array}$ & $\begin{array}{l}A_{1}=-4.5780 \times 10^{-4} \\
A_{2}=-0.4617 \\
A_{3}=0.6016 \\
A_{4}=0.5649\end{array}$ & $-30 \cdot 0829$ & $0 \cdot 2424$ & 0.9766 & $20 \cdot 665$ \\
\hline $\begin{array}{l}E_{\text {HOMO }} \\
E_{\mathrm{LUMO}} \\
\delta E \\
E_{\text {total }}\end{array}$ & $\begin{array}{l}A_{1}=0.0996 \\
A_{2}=-0.6350 \\
A_{3}=-7 \cdot 0000 \times 10^{-15} \\
A_{4}=0.4824\end{array}$ & -25.9896 & $0 \cdot 2264$ & 0.9745 & 31.444 \\
\hline $\begin{array}{l}\mathrm{W} \\
E_{\text {HOMO }} \\
E_{\mathrm{LUMO}} \\
E_{\text {total }}\end{array}$ & $\begin{array}{l}A_{1}=-4.5780 \times 10^{-4} \\
A_{2}=0 \cdot 1399 \\
A_{3}=-0.6016 \\
A_{4}=0.5649\end{array}$ & $-30 \cdot 0829$ & $0 \cdot 2424$ & 0.9766 & $20 \cdot 665$ \\
\hline $\begin{array}{l}\mathrm{Sz} \\
E_{\mathrm{HOMO}} \\
E_{\mathrm{LUMO}} \\
E_{\text {total }}\end{array}$ & $\begin{array}{l}A_{1}=-6.5682 \times 10^{-4} \\
A_{2}=0.0375 \\
A_{3}=-0.5123 \\
A_{4}=0.6657\end{array}$ & $-34 \cdot 3806$ & $0 \cdot 1887$ & 0.9859 & $34 \cdot 742$ \\
\hline
\end{tabular}

antitubercular activities of quinolones. However, moderate collinearities exist between $\delta E$

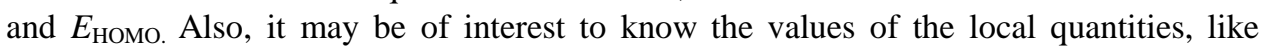
charge, Fukui function or local softness at the active sites of the compounds and how these are related to the activity. However, we could not make such calculations due to unavailability of software. Furthermore, such local counterparts to the topological indices, Wiener or Szeged, are not known.

The data presented in table 2, i.e. the correlation matrix, are important for investigating statistically significant QSAR models as well as the inter-collinearities existing between (i) W and $\mathrm{Sz}$, (ii) $\mathrm{W}$ and $E_{\text {total }}$, and (iii) $\mathrm{Sz}$ and $E_{\text {total }}$. A good correlation exists between $E_{\mathrm{HOMO}}$ and $\delta E$. 
Table 5. Comparison of estimated $c \log P$ values of the quinolones with those reported in table 1.

Residue $=$ difference between observed and estimated $c \log P$

\begin{tabular}{|c|c|c|c|c|c|c|c|}
\hline \multirow[b]{3}{*}{ Compound } & \multirow[b]{3}{*}{ Obs. $c \log P$} & \multicolumn{5}{|c|}{ Estimated $c \log P$} & \\
\hline & & \multicolumn{2}{|c|}{ I } & \multicolumn{2}{|c|}{ II } & \multicolumn{2}{|c|}{ III } \\
\hline & & (7) & Residue & (8) & Residue & (9) & Residue \\
\hline I & $3 \cdot 81$ & $3 \cdot 96$ & $-0 \cdot 15$ & $3 \cdot 90$ & -0.09 & $3 \cdot 82$ & $-0 \cdot 01$ \\
\hline II & $4 \cdot 67$ & $4 \cdot 26$ & $0 \cdot 41$ & $4 \cdot 33$ & $0 \cdot 34$ & $4 \cdot 44$ & $0 \cdot 23$ \\
\hline III & $4 \cdot 33$ & $4 \cdot 44$ & $-0 \cdot 11$ & $4 \cdot 38$ & $-0 \cdot 05$ & $4 \cdot 41$ & $-0 \cdot 08$ \\
\hline IV & $4 \cdot 85$ & $5 \cdot 00$ & $-0 \cdot 15$ & 4.93 & $-0 \cdot 08$ & $5 \cdot 01$ & $-0 \cdot 16$ \\
\hline V & $4 \cdot 86$ & $5 \cdot 13$ & $-0 \cdot 27$ & $5 \cdot 01$ & $-0 \cdot 15$ & 4.95 & -0.09 \\
\hline VI & $5 \cdot 20$ & $5 \cdot 07$ & $0 \cdot 13$ & $5 \cdot 36$ & $-0 \cdot 16$ & $5 \cdot 28$ & $-0 \cdot 08$ \\
\hline VII & $5 \cdot 51$ & $5 \cdot 45$ & $0 \cdot 06$ & $5 \cdot 44$ & $0 \cdot 06$ & $5 \cdot 38$ & $0 \cdot 13$ \\
\hline VIII & $6 \cdot 12$ & $6 \cdot 03$ & 0.09 & $6 \cdot 11$ & $0 \cdot 01$ & $6 \cdot 21$ & -0.09 \\
\hline IX & $6 \cdot 25$ & $6 \cdot 26$ & $-0 \cdot 01$ & $6 \cdot 16$ & 0.09 & $6 \cdot 11$ & $0 \cdot 14$ \\
\hline
\end{tabular}

Similarly, the correlation matrix shows that high collinearity exists between $E_{\text {total }}$ and $\log P$; while good collinearity is found between $\mathrm{W}$ and $\log P$ as well as $\mathrm{Sz}$ and $\log P$. Thus, monoparametric QSAR models are possible with each of these three molecular descriptors i.e. W, Sz and $E_{\text {total }}$ and that multiparametric correlations involving these parameters will be statistically significant.

Several univariate as well as multivariate correlations between the structural parameters mentioned above and $c \log P$ are presented in table 4 .

As seen from the correlation matrix (table 2), W, Sz and $E_{\text {total }}$ are the best suited parameters for univariate correlation analysis. Regression parameters and correlations given in table 4 confirm this finding.

Hence, if $T I$ stands for one of the parameters $\mathrm{W}, \mathrm{Sz}$ or $E_{\text {total }}$ then,

$$
c \log P=A T I+B,
$$

here $A$ and $B$ represent the corresponding regression coefficients.

A perusal of table 4 indicates that $E_{\text {total }}$ is an excellent parameter for correlating $c \log P$ values of the quinolones. Therefore,

$$
c \log P=(0.4692) E_{\text {total }}-24.9894 .
$$

In bivariate correlation analyses also, the correlations involving $E_{\text {total }}$ and $\mathrm{W}$ or $\mathrm{Sz}$ are found to be excellent. However, bivariate correlations involving $\mathrm{Sz}$ were found to be better than those in which $\mathrm{W}$ is involved. Excellent correlation (0.9809) is obtained when in bivariate correlation $\mathrm{Sz}$ and $E_{\text {total }}$ were used. The correlation is expressed as:

$$
c \log P=\left(6.9445 \times 10^{-4}\right) \mathrm{Sz}+(0 \cdot 6669) E_{\text {total }}-34 \cdot 1581 .
$$

An excellent correlation is also obtained in tervariate correlations involving $\mathrm{W}, \mathrm{Sz}$ and $E_{\text {total }}$ on the one hand and $\mathrm{Sz}, E_{\mathrm{HOMO}}$ and $E_{\text {total }}$ on the other. The correlation coefficients in both the cases were found to be approximately the same (0.9828), the standard deviation of the latter $(0 \cdot 1858)$ was found to be slightly smaller than the standard deviation in the former $(0 \cdot 1861)$. This indicates that the tervariate correlation: $\mathrm{Sz}-E_{\mathrm{HO} O}-E_{\mathrm{total}}$ is better than the correlation $\mathrm{W}-\mathrm{Sz}-E_{\text {total }}$. 
It is interesting to note that the tervariate correlation involving $\mathrm{Sz}-E_{\mathrm{HOMO}}-E_{\text {total }}$ $(0.9859)$ is excellent in all the 27 correlations investigated by us. The tetravariate correlation involving $\mathrm{Sz}-E_{\mathrm{HOMO}}-E_{\mathrm{LUMO}}-E_{\mathrm{total}}$ has the same correlation potential (0.9859). However, its standard deviation (0.1887) is much higher than the trivariate correlation discussed above $(0 \cdot 1690)$. This clearly indicates that the antitubercular activity of the quinolones under the present study is excellently modelled by the tervariate correlation. Thus, the correlation expression can be written as:

$$
c \log P=\left(-6.6051 E \times 10^{-4}\right) \mathrm{Sz}-(0.4718) E_{\mathrm{LUMO}}+(0.6650) E_{\mathrm{total}}-34.3017 .
$$

The data presented in table 4 clearly indicate that the quality of correlation increases as we pass from univariate to tetravariate correlations. Also, the results indicate that multiple correlations give better estimates than the univariate correlations and that the multivariate correlations wherein $\mathrm{Sz}$ is involved are better than those correlations where $\mathrm{W}$ is involved.

As seen from table 4, it is possible to quite accurately estimate the values of $c \log P$ (expressing antitubercular activities) of the quinolones under present study. Thus, using the distance-based topological indices $\mathrm{W}$ and $\mathrm{Sz}$ as well as molecular orbital energies, it is possible to infer the pharmacological activities of these substances. All the five molecular descriptors (W, Sz, $E_{\mathrm{HOMO}}, E_{\mathrm{LUMO}}$ and $\left.E_{\text {total }}\right)$ have practically the same predictive ability, the Szeged index $(\mathrm{Sz})$ being slightly better (in multivariate correlations) than the remaining molecular descriptors.

All the tetravariate correlations involving $E_{\mathrm{HOMO}}$ and $E_{\mathrm{LUMO}}$ have correlation coefficients approximately of the order of 0.9766 . This suggests a possibility of charge transfer (CT) from the drug (quinolones) to the receptor. Of greater interest is the fact that the energy difference $\delta E\left(=E_{\mathrm{HOMO}}-E_{\mathrm{LUMO}}\right)$ also gives excellent results in multivariate correlations. This indicates that potency increases with decreasing gap magnitude and a concerted CT is suggested between the drug's (quinolone's) $\pi$-HOMO and an unoccupied orbital of the receptor, and the drug's (quinolone's) $\pi$-LUMO and an occupied orbital of the receptor.

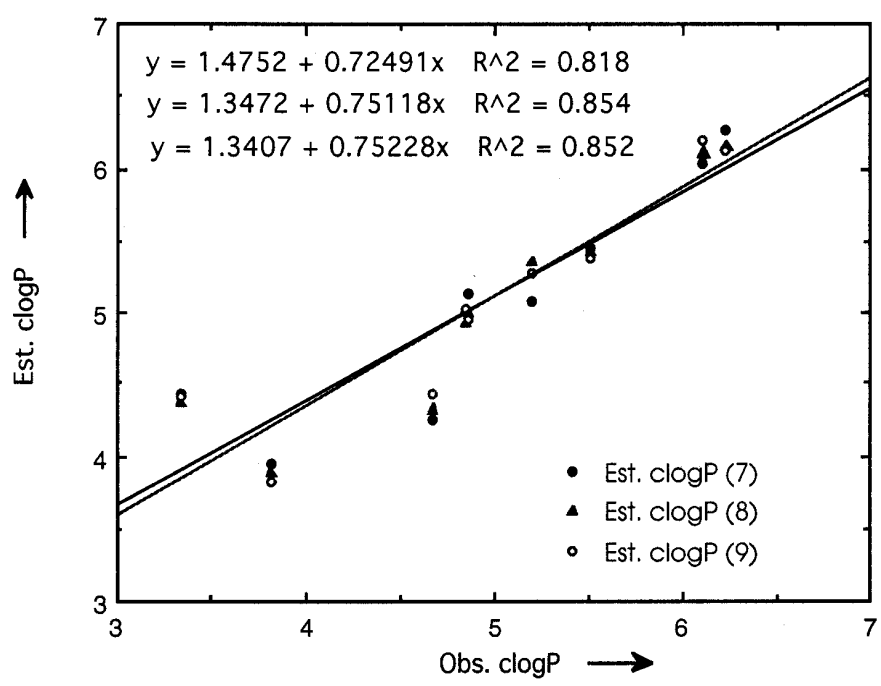

Figure 2. Correlation of observed with estimated $c \log P$. 
Finally, in order to confirm our findings, antitubercular $(c \log P)$ activities predicted by (7), (8) and (9) are compared with the corresponding $c \log P$ values reported in table 1. Such a comparison is shown in table 5 . Within experimental error, the values agree well.

Finally, a plot is obtained between the observed and estimated $c \log P$ as shown in figure 2 wherein all the three equations (7), (8) and (9) are used for estimating $c \log P$ respectively. $R^{2}$ values $(0.818,0.854$, and 0.852$)$ obtained for each of these equations confirm our findings.

\section{Conclusion}

Analysis of this limited set of quinolone molecules allowed us to build a model of antitubercular activity in which W, Sz, $E_{\mathrm{HOMO}}, E_{\mathrm{LUMO}}, \mathrm{d} E$ and $E_{\text {total }}$ are important factors. This, in turn, will help pharmacologists as well as medicinal chemists in the prediction of increased activity and thus the synthesis of hitherto unknown quinolone(s) exhibiting better antitubercular activities than those reported in this paper.

\section{Acknowledgement}

One of the authors VKA thanks the All India Council for Technical Education, New Delhi for financial support. The authors thank Prof. A Wissner for providing his software for making molecular orbital calculations.

\section{References}

1. Trinajstic N 1992 Chemical graph theory 2nd edn (Boca Raton, FL: CRC Press)

2. Wiener H 1947 J. Am. Chem. Soc. 6917

3. Gutman I, Yeh Y N, Lee S L and Luo Y L 1993 Indian J. Chem. A32 651

4. Bangadia R, Khadikar P V and Agrawal J K 1999 Indian J. Chem. A38 170

5. Khadikar P V, Karmarkar S, Sharma S, Seervani A D and Joshi S 1997 J. Serb. Chem. Soc. 62 219

6. Gutman I and Kortvelyesi T 1995 Z. Naturforsch. A50 669

7. Gutman I 1994 Graph theory notes, New York 2727

8. Khadikar P V, Deshpande N V, Kale P P, Dobrynin A, Gutman I and Domotor G 1995 J. Chem. Inf. Comput. Sci. 35547

9. Gutman I, Popovic L, Khadikar P V, Karmarkar S, Joshi S and Mandloi M 1997 Commun. Math. Comput. Chem. (MATCH) 3591

10. Gutman I, Khadikar P V and Khaddar T 1997 Commun. Math. Comput. Chem. (MATCH) 35 105

11. Gutman I, Khadikar P V, Rajput P V and Karmarkar S 1995 J. Serb. Chem. Soc. 60759

12. Renau T E, Sanchez J P, Gage J W, Dever J A, Shapiro M A, Gracheck S J and Domagala J M 1996 J. Med. Chem. 39729

13. Franke R 1984 Theoretical drug design methods (New York: Elsevier)

14. Parr R G and Pearson R G 1983 J. Am. Chem. Soc. 1057512

15. Pearson R G and Palke W E 1992 J. Phys. Chem. 963283

16. Buckley F and Hararay F 1990 Distance in graphs (Reading, MA: Addison-Wesley)

17. Wissner A 1990 (personal communication)

18. Renau T E, Sanchez J P, Gage J W, Dever J A, Shapiro M A, Gracheck S J and Domagala J M 1995 J. Med. Chem. 382974

19. Parr R G and Chattaraj P K 1991 J. Am. Chem. Soc. 1131854

20. Pal S, Vaval N and Roy K K 1993 J. Phys. Chem. 974404 